\title{
Merging and Migration of Two Medidies
}

\author{
Kathy L. SChUlTZ TOKOS, HaNS-HARALD HinRICHSEN, AND WALTER ZENK \\ Institut für Meereskunde an der Universität Kiel, Kiel, Germany
}

(Manuscript received 28 September 1993, in final form 14 February 1994)

\section{ABSTRACT}

\begin{abstract}
In this study a scenario is developed of two adjacent Mediterranean Water eddies (meddies) as they were observed merging and drifting through the Iberian Basin. Observations are based on four RAFOS floats (at $850-1050 \mathrm{dbar}$ ), two hydrographic surveys (centered roughly at $38^{\circ} \mathrm{N}, 24^{\circ} \mathrm{W}$ ), and trajectories of surface drifters (drogued at $100 \mathrm{~m}$ ). In April 1991, the meddy A was identified and labeled by surface drifters. During the revisit one month later two meddies were encountered, $B 1$ and $B 2$, in the vicinity of the former meddy $A$. The coalescence of $\mathrm{B} 1$ (subsequently identified as $\mathrm{A}$, one month older) and $\mathrm{B} 2$ is inferred from a simple kinematic model describing the observed movement of the RAFOS floats for up to three months after the second CTD survey. The deduced vorticity front, radius $\sim 15 \mathrm{~km}$, within $B 1$ was of insufficient strength to keep the core waters of $\mathrm{B} 1$ isolated and prevent the absorption of $\mathrm{B} 1$ by $\mathrm{B} 2$. The resulting meddy $(\mathrm{B} 1+\mathrm{B} 2)$ showed a clear near-surface dynamical signal. Its deep root $(1800 \mathrm{~m})$ could explain the expulsion from the meddy of the remaining RAFOS float and surface drifter at the time of the meddy's collision with the Josephine Seamount. For the first time, a set of Lagrangian and hydrographic observations give direct evidence that neighboring meddies can merge as predicted by theoretical considerations.
\end{abstract}

\section{Introduction}

Meddies (Mediterranean Water eddies) have been generally accepted as a significant mechanism for the distribution of conservative properties in the eastern North Atlantic Ocean (Lillibridge and Rossby 1983; McWilliams 1985; Armi et al. 1989; Ambar et al. 1992). A "typical" meddy can be recognized by its large anomalies of heat and salt, approximately $2.5^{\circ} \mathrm{C}$ and $0.8 \mathrm{psu}$, respectively. This strong signal can span $1200 \mathrm{~m}$ vertically and $100 \mathrm{~km}$ horizontally (this work). The question, however, of how they distribute temperature and salinity remains at least in part unanswered and is being addressed in current investigations.

Several meddies have been observed and studied in detail. The most intensive study to date has been of a meddy named Sharon in the Canary Basin (Armi et al. 1989; Hebert et al. 1990; Richardson et al. 1989; Rossby 1988; Schultz Tokos and Rossby 1991). It was followed using neutrally buoyant SOFAR floats for over two years, during which time four surveys were conducted with a wide array of instrumentation. This meddy was shown to move slowly to the south, losing the bulk of its heat and salt through lateral intrusions that transported properties away from the core of the lens (Armi et al. 1989), assumedly leaving a warm and salty trail in its wake. In fact, a salty wake of another

Corresponding author address: Kathy L. Schultz Tokos, Institut für Meereskunde an der Universität Kiel, Düsternbrooker Weg 20, D-24105 Kiel, Germany.
Canary Basin meddy has been observed by Käse and Zenk (1987). However, if southward movement and steady loss of salt were the only spreading mechanism of a meddy, one might expect the Mediterranean salt tongue to have a more southward, rather than westward extension.

Although one meddy is reported to have survived passing between two seamounts (Shapiro et al. 1992), another meddy followed with SOFAR floats apparently collided with the Hyeres Seamount (Richardson et al. 1989). Collisions would result in a sudden deposit of a meddy's anomalous heat and salt content, rather than, or in addition to, leaving a steady trail.

Beckmann and Käse (1989), using a quasigeostrophic model, showed self-propulsion to the south for isolated features, and in almost any direction where there is an interaction of more than one eddy. They noted that the $\beta$ effect is primarily responsible for southward movement, which is modified to the west with increasing significance of the nonlinear terms. Rotating tank models have also shown decay mechanisms through the "sloughing off" of meddy pieces as it transforms from an unstable, elliptical state, to a stable, circular one (Hedstrom and Armi 1988).

The objective of ongoing research at the Institut für Meereskunde (IfM), Kiel, Germany, is to determine sites of meddy generation, the mechanisms and characteristics of meddy movement, and the subsequent mixing of meddies with the background North Atlantic waters. The interplay between oceanographic observations and theoretical modeling is proving to be a successful approach to understanding these processes. 

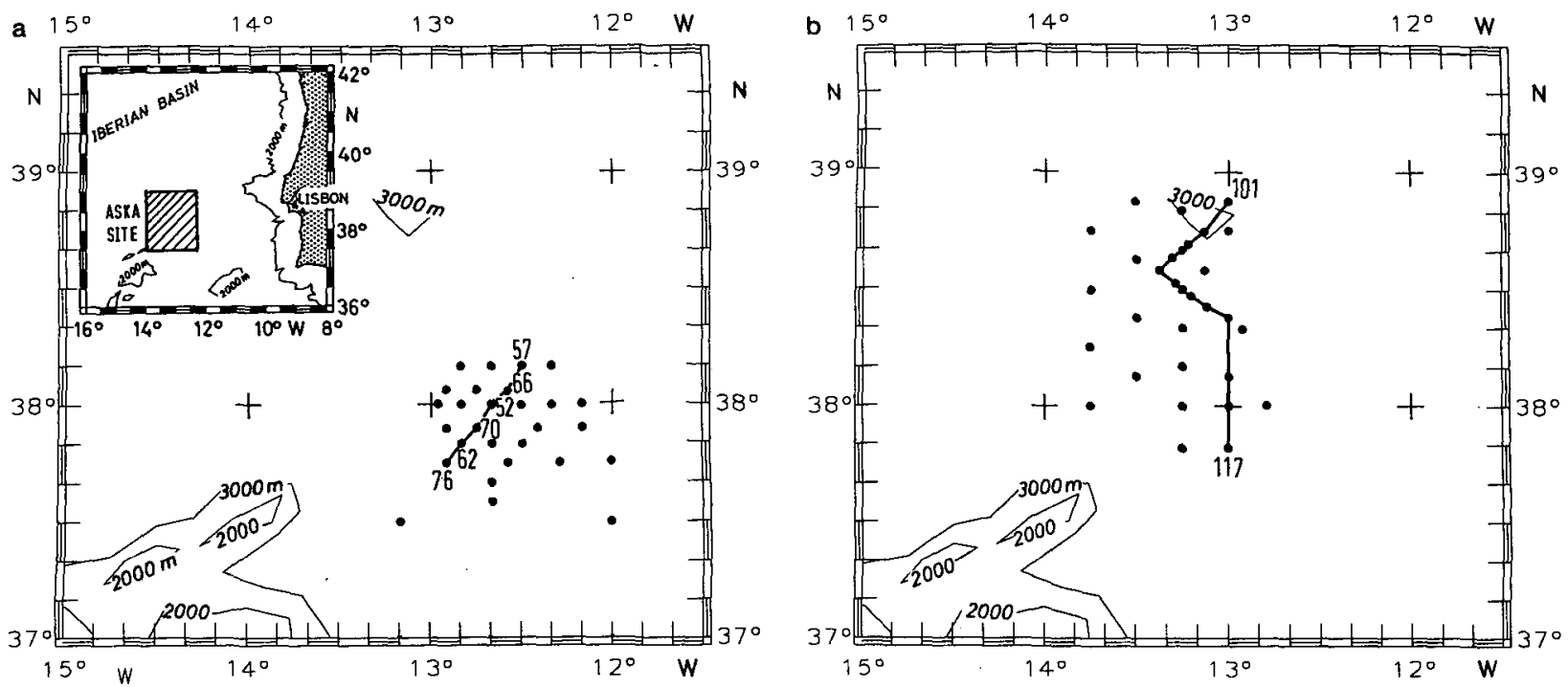

FIG. 1. Poseidon 182 cruise track for April (a) and May (b), showing CTD stations (dots) and selected station numbers and RAFOS float launch sites (squares).

In this paper we present the results of a recent experiment in the Iberian Basin. This and previous studies (Hinrichsen et al. 1993; Käse et al. 1989) lead us to conclude that the Iberian Basin is a dynamically active regime for meddies, which may be in contrast to the "quieter" Canary Basin. Shapiro et al. (1992) describe self-similarity criteria that also contrast Iberian Basin and Canary Basin meddies. Meddies have been observed in very close proximity to each other in the Iberian Basin (Hinrichsen et al. 1993), which is also the case in this experiment, whereas available observations of meddies in the Canary Basin have all been of isolated features. In addition, Iberian Basin meddies can have a dynamic signal reaching to the surface (Stammer et al. 1991; Siedler et al. 1985). A meddy surface expression was also observed in the far northern Canary Basin (Käse and Zenk 1987), whereas the dynamical signal of Sharon, deep within the Canary Basin, did not reach the surface. A meddy's surface expression is again confirmed in the present study with the use of ARGOS satellite-tracked surface drifters.

This experiment consisted of two hydrographic surveys, one month apart, conducted in a meddy named Aska. Relocation of the meddy during the second cruise was possible with up-to-the-minute ARGOS positions of surface drifters launched within the meddy on the first cruise, one of which stayed in Aska for over five weeks.

Also during the second visit to Aska, RAFOS floats (Rossby et al. 1986) were launched to approximately map the movement of water within the meddy at depth. RAFOS (ranging and fixing of sound) floats are neutrally buoyant underwater drifters that, along with temperature and pressure, record the travel time of signals from two or more sound sources, enabling position determination. Additional surface drifters drogued to 100-m depth were also launched to determine the mean vertical shear and to investigate further the communication between the meddy and the sea surface.

From four RAFOS float trajectories and accompanying hydrography, we have observed to our surprise not one, but two meddies, and their interaction. In the following sections we present the observations, which show that one meddy was actually absorbed by the other. In section 3 the total salt and heat content of the meddy is calculated. Section 4 presents the evidence of the absorption and Aska's migration over three months, including the influence of bottom topography on the coherency of the meddy. Next, we discuss the large pressure variations recorded by the RAFOS floats and their implications.

\section{Observations}

\section{a. CTD surveys}

The CTD data were obtained on FS Poseidon in 1991 during April and May (Fig. 1). Each CTD survey was done in 4-5 days, which yielded two independent, quasi-synoptic datasets. Acquisition of CTD data was performed as described in Käse et al. (1989) accompanied by a data reduction to approximately 0.8 dbar vertical resolution for onboard analysis.

The first CTD survey took place between 13 and 18 April with most stations reaching a pressure of 4000 dbar. Figure 2 shows the quasi-synoptic salinity field for April at the 1000-dbar level, to be comparable with representations of the classic picture of the long-term averaged large-scale Mediterranean core layer salinity (Wüst 1936; Worthington 1976; Maillard 1986). In contrast to the historical mean field, our survey reveals 


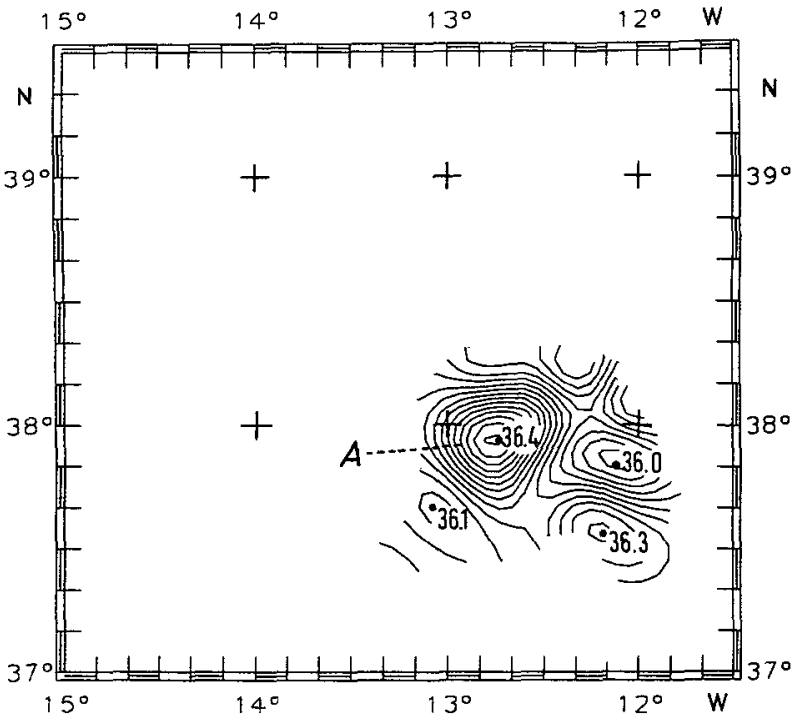

Fig. 2. Salinity at $1000 \mathrm{dbar}$ during the first visit to Aska (Part A) in April 1991. Contour interval is 0.025 .

strong spatial variability in salinity (36.02-36.40 psu ). In our submesoscale $\left(10^{3} \mathrm{~km}^{2}\right)$ quasi-synoptic survey, the salinity maximum occurs in the area around $38^{\circ} 00^{\prime} \mathrm{N}, 12^{\circ} 45^{\prime} \mathrm{W}$ as a subsurface eddy, referred to as part "A" of Aska. The variability of the salinity field in the horizontal map has a smoothed character due to the application of an objective analysis method (Hiller and Käse 1983) using a Gaussian covariance function with an isotropic scale of $25 \mathrm{~km}$. Shown are results of less than $75 \%$ mean variance error. The fresher (and colder) water "patches" (closed contours) outside of the meddy are an artifact of the analysis (represented by one or fewer data points) and chosen mean variance error limit, and have no dynamical signal. Unfortunately, the background field of the area to the west could not be resolved sufficiently due to lack of available ship time. Several horizontal property maps of $A$ at various levels reveal a meddy diameter of approximately $60 \mathrm{~km}$.

Figures $3 a-c$ show the vertical distribution of the potential temperature, salinity, and geostrophic velocities referenced to $3000 \mathrm{dbar}$ on a section running from southwest to northeast through the center of $A$, as marked in the station map (Fig. 1a). The water properties of the meddy are similar to those of the Mediterranean Water outflow along the Portuguese shelf break near Cape St. Vincent. There exists a double property maximum with an upper, warmer, and less saline core centered around $800-\mathrm{m}$ depth, and a lower one at approximately $1300 \mathrm{~m}$, the level of the intermediate salinity maximum (Zenk and Armi 1990). The temperature in the upper core was more than $12.5^{\circ} \mathrm{C}$ in the center with salinity greater than 36.2 psu, whereas the lower core had a maximum temper- ature and salinity of $\mathrm{T}=11.9^{\circ} \mathrm{C}$ and $S>36.5 \mathrm{psu}$, respectively.

The corresponding geostrophic velocities yield the expected anticyclonic circulation with maximum speeds at the southern edge of more than $25 \mathrm{~cm} \mathrm{~s}^{-1}$. In agreement with recent altimetry investigations of meddy movements (Stammer et al. 1991), our hydrographic observations also reveal a significant near-surface signature of the meddy (Fig. 3c), indicated by anticyclonic circulation with velocities generally larger
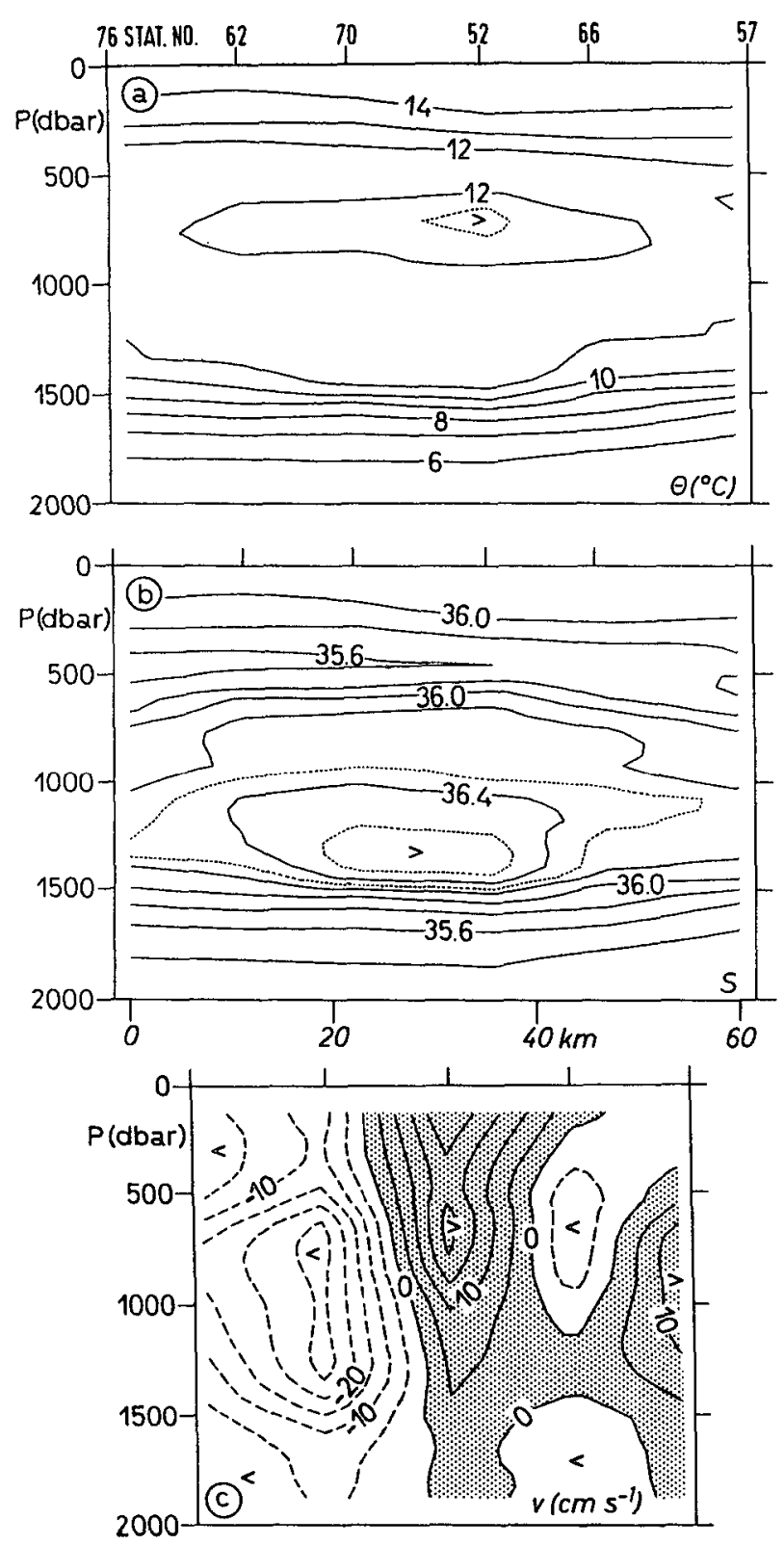

FIG. 3. Hydrographic section through Meddy Aska (Part A) April 1991 as shown in Fig. la.: (a) potential temperature, (b) salinity, (c) geostrophic velocity referenced to 3000 dbar (positive northwestward). 


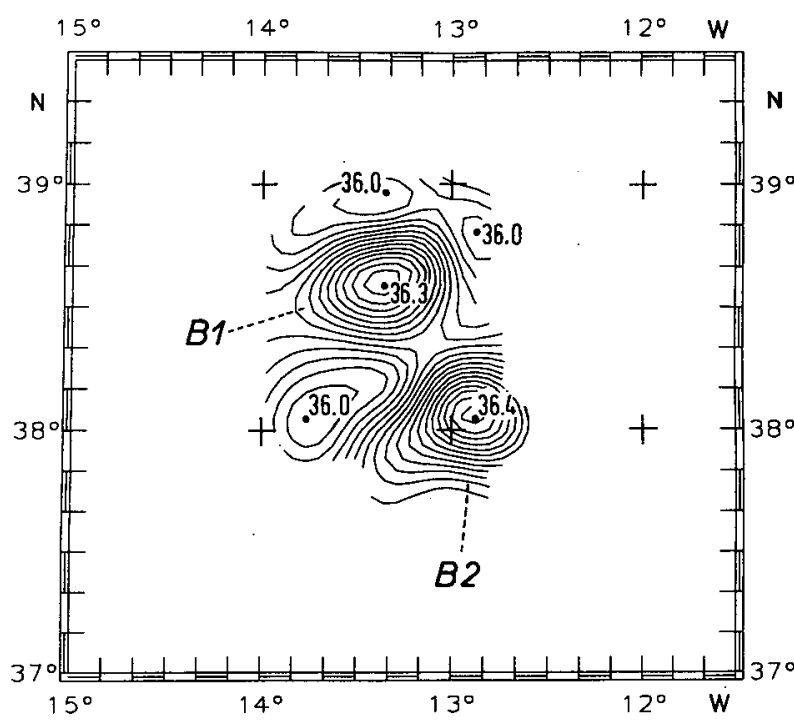

FIG. 4. Salinity at 1000 dbar during the second visit to Aska in May 1991. Two meddies are discernible, B1 and B2. Contour interval is 0.025 .

than $10 \mathrm{~cm} \mathrm{~s}^{-1}$. A surface drifter launched during the hydrographic survey also showed rotational velocities of this order.

The local geostrophic mass transport between 500 and 1500 dbar was $\sim 6 \mathrm{~Sv}\left(\mathrm{~Sv} \equiv 10^{6} \mathrm{~m}^{3} \mathrm{~s}^{-1}\right)$. The maximum vertically integrated transport and maximum salinity were contained in an inner circulation cell offset slightly to the southwest.

From 24 to 27 May 1991, Poseidon operated in the same area to relocate Aska (Fig. 1b). A special aim of the second leg was to obtain more insight into temporal modifications of the meddy by launching RAFOS floats in conjunction with a repeat hydrographic survey.

Reasons why we assumed we would find Aska again included:

- a study of meddy movement utilizing a quasigeostrophic prognostic model (Käse et al. 1989) and results of the hydrographic observations from the first leg were encouraging,

- trajectories of satellite tracked surface drifters launched during the first leg appeared to trace the movement of a meddy, and

- a snapshot-like survey of the temperature distribution within the same region by deep-reaching expendable bathythermograph probes between CTD surveys was in agreement with the meddy observation during the first leg.

The hydrographic observations of the second leg unexpectedly yielded two property maxima in the horizontal (Fig. 4). The salinity field at $1000 \mathrm{dbar}$ is dumbbell shaped with the two maxima $75 \mathrm{~km}$ apart. The pattern can be divided into two separate meddies, B1 and B2, located on a northwest-southeast axis. The southern meddy, B2, is distinguished by slightly higher salinity values in the center, being 0.1 psu more saline than the northern one, B1. Various representations of the property fields of the meddy located to the north indicate great conformity with that part of the Aska system examined during the first leg in April (" $A$ " in Fig. 2).

In Figs. 5a-c the same parameters as in Fig. 3 are shown but for the second survey. It represents a section constructed in such a way that the centers of each meddy would be included (see Fig. 1b). The northern meddy (B1) had the same vertical double maximum shape and had almost identical property distributions as $\mathrm{A}$. The largest geostrophic velocities $\left(>30 \mathrm{~cm} \mathrm{~s}^{-1}\right)$ were observed at the northern edge of $\mathrm{B} 1$ and at the

(a)

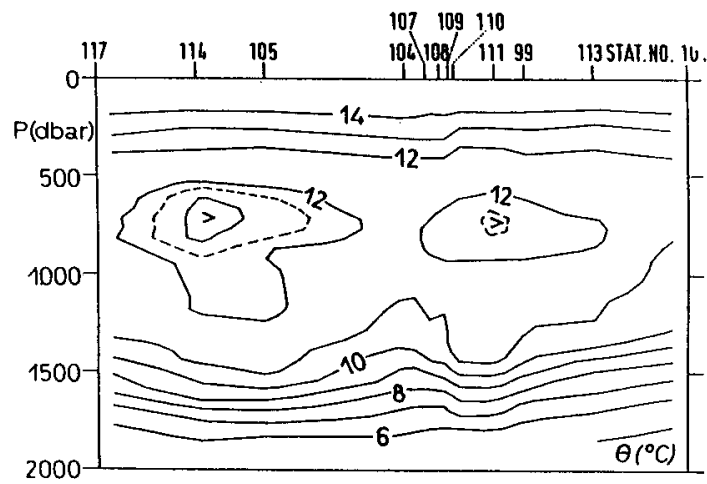

(b)

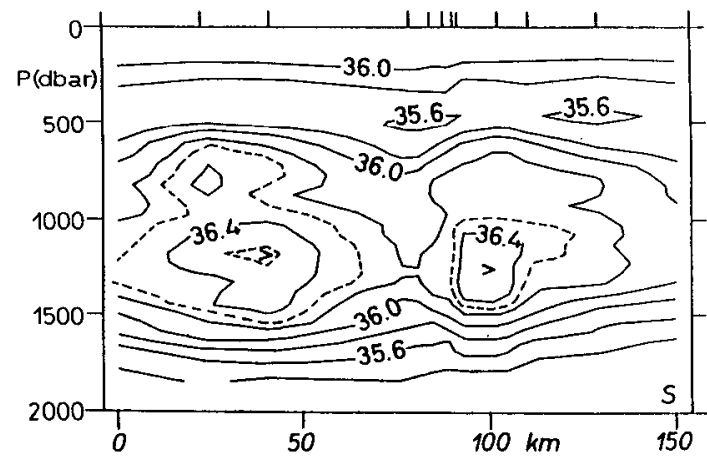

(c)

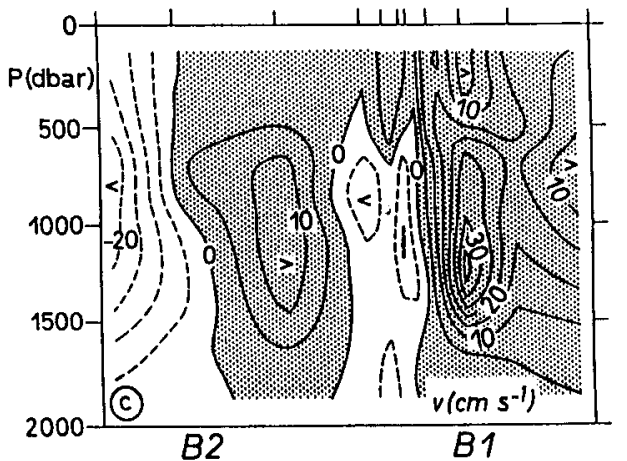

FIG. 5. Hydrographic section through Meddy Aska parts B1 and B2 in May 1991 as shown in Fig. 1b.: (a) potential temperature, (b) salinity, (c) geostrophic velocity referenced to $3000 \mathrm{dbar}$ (positive westward). 


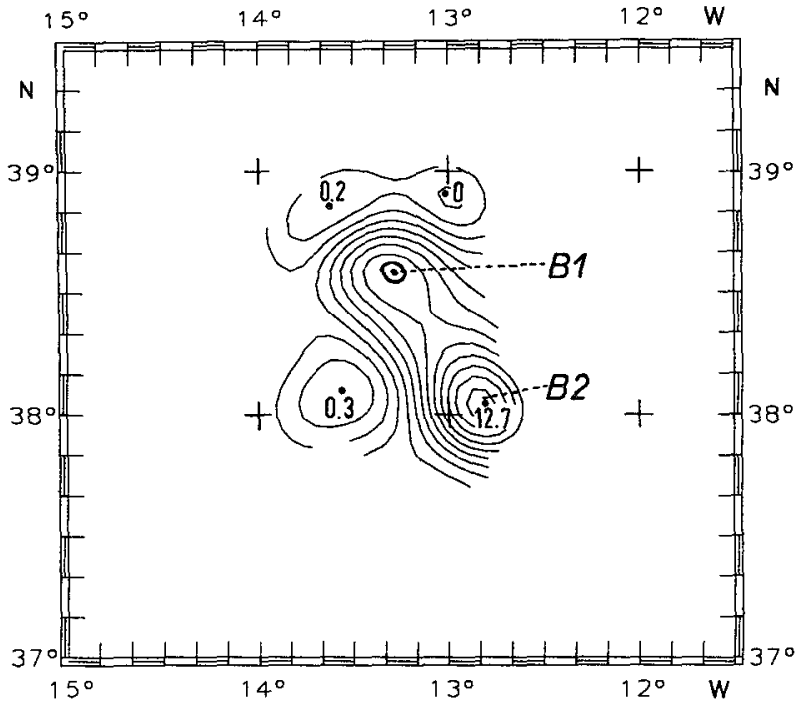

FIG. 6. Geostrophic streamfunction for the MW layer (500-1500 dbar) during the second visit to Aska. Contour interval is $1 \mathrm{~m}^{4} \mathrm{~s}^{-1}$ referenced to $3000 \mathrm{dbar}$.

southern periphery of B2 $\left(>20 \mathrm{~cm} \mathrm{~s}^{-1}\right)$. The velocity field indicates two separate anticyclonically rotating lenses with lower speeds $\left(10 \mathrm{~cm} \mathrm{~s}^{-1}\right)$ between their centers due to weaker horizontal gradients in the temperature and salinity fields. A larger circulation encompassed both the northern, B1, and southern, B2, parts of the meddy system (Fig. 6). Inside this coherent circulation scheme the inner part of the southern meddy had higher eddy kinetic energy. The transport within B2 was $8 \mathrm{~Sv}$, whereas the transport within B1 was only $4 \mathrm{~Sv}$.

\section{b. RAFOS floats}

Underwater, free-drifting RAFOS floats are well suited for the study of meddies. Their quasi-Lagrangian nature is ideal for following fluid motion within the moving, rapidly evolving reference frame of a meddy. The RAFOS floats used for this study are similar to those described by Rossby et al. (1986). The modified RAFOS technology used at If M Kiel has been recently documented by König and Zenk (1992). Isobaric floats were used, that is, floats whose compressibility is much less ( some 25\%) than that of seawater. This means that float motion is not identical to that of an isopycnal fluid parcel in regions of strong vertical motion. However, the horizontal velocity field should still be well described where vertical shear is limited.

RAFOS floats were launched in B1 of the Aska system during the second CTD survey. We discuss here the data returned from four floats, launched at the center and at radii of 20 and $30 \mathrm{~km}$ (Fig. 1b). Two of the floats were programmed to return data after 11 months, recording temperature, pressure, and navigational data once a day to study the longer timescale changes of Aska. Of these, one float returned early, yielding almost three weeks of valid data. The other two floats were programmed to take measurements every four hours for one month. These four floats have revealed a surprisingly consistent evolution of Aska during the period of observation, which will be discussed in the following sections.

\section{c. Surface drifters}

A total of six ARGOS satellite-tracked drifters drogued to $100 \mathrm{~m}$ were launched during the two cruise legs. Two of the three drifters launched during Leg 1 remained in Aska (Fig. 7), enabling relocation and positive identification of the meddy during the second leg. Three more drifters were launched during the second hydrographic survey. Two of these were expelled from Aska almost immediately. The remaining drifter remained trapped within Aska's near-surface circulation for over three months.

\section{Physical properties: April-May 1991}

In this section, we estimate the vertical and horizontal dimensions and the total heat and salt content of the observed meddies. In addition, we calculate temporal changes during the six weeks between our two hydrographic surveys. Since salinity at middepth reached at least 35.7 psu for all CTD casts done within the Iberian Basin, we calculate all property anomalies by vertically integrating over areas in excess of this value.

The horizontal distribution of the vertically integrated salt anomaly for both hydrographic surveys is

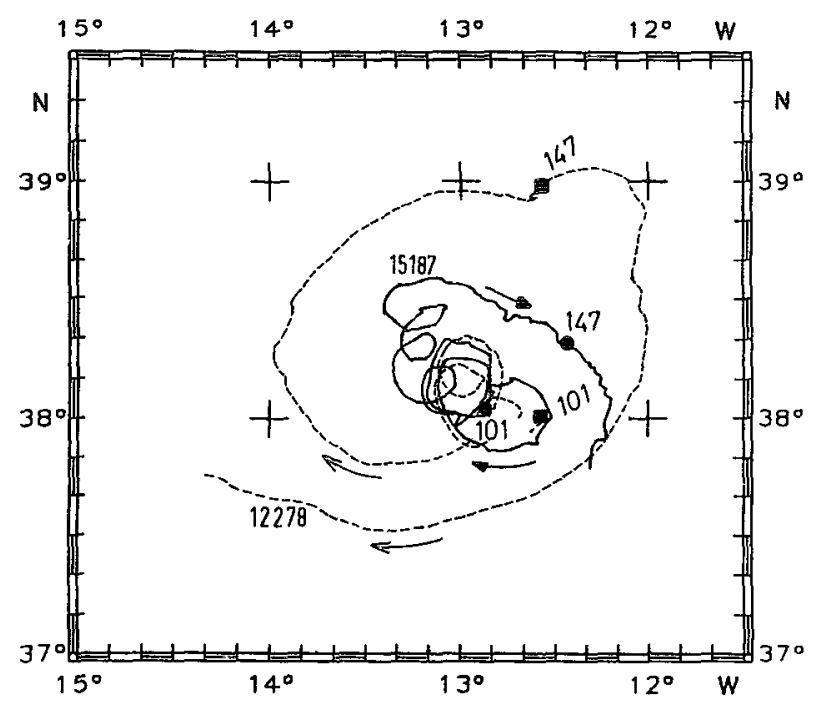

FIG. 7. Trajectories of two surface drifters, 12278 (dashed line, yeardays denoted by small boxes) and 15187 (solid line, yeardays denoted by dots) launched on the first cruise leg to relocate meddy. 
shown in Fig. 8. The diameter of each meddy was defined by the first closed contour line $\left(400 \mathrm{~kg} \mathrm{~m}^{-2}\right)$.

The salt contents of $\mathrm{A}, \mathrm{B} 1$, and $\mathrm{B} 2$ are double that of the background field. Vertically integrated quantities for all three features are characterized by almost constant values within radii of $10 \mathrm{~km}$ from the center and stronger gradient regions farther away. The vertical extension of the anomaly varies from 1150 dbar at the centers to 1000 dbar at the outer edges of A and B1. Meddy B2 contains 20\% more salt than either of the other center areas due to its greater vertical extent at the center ( $1250 \mathrm{dbar}$ ). Significant differences were also obtained for the mean horizontal scales. The diameter of A was $15 \mathrm{~km}$ greater than that of B1, whereas B2 was even larger horizontally. Property amounts and spatial scales are displayed in Table 1.

\section{Kinematic properties: May-August 1991}

In this section we examine the evolution of the Aska Meddy system using four RAFOS floats, two of whose trajectories are shown in Fig. 9. The dots in the figure represent 8-hour positions, the numbers labeling starred positions correspond to yearday in 1991. All four floats were launched in B1 of Aska at a time when we were not yet aware of the existence of B2: R(AFOS float) 24 at the horizontal salinity maximum, R21 and R25 about $20 \mathrm{~km}$ away, and $\mathrm{R} 10$ at a radius of $30 \mathrm{~km}$ (see Fig. 1b). With these four floats we observe for the first time an interaction between two meddies. The floats all made at least one revolution around $B 1$, then, at various times, they left $\mathrm{B} 1$ and joined the closed circulation of B2, which evidences an exchange of fluid between the two meddies.

The transition from one lens (B1) to another (B2) is recognized first in the trajectories themselves. The
TABLE 1. Integrated properties and spacial scales of Meddy Aska for repeated visits. The first value of the thickness represents the outer edge, the second value the center. Plus-minus values represent one standard deviation.

\begin{tabular}{lccc}
\hline & April 1991 & \multicolumn{2}{c}{ May 1991 } \\
\cline { 2 - 4 } \cline { 4 - 4 } \cline { 4 - 4 } & & Part \\
\cline { 2 - 4 } & $\mathrm{A}$ & $\mathrm{B} 1$ & $\mathrm{~B} 2$ \\
\hline Thickness $(\mathrm{dbar})$ & $1000-1120$ & $1020-1150$ & $1000-1250$ \\
Diameter $(\mathrm{km})$ & $\sim 65$ & $\sim 50$ & $\sim 75$ \\
Volume $\left(10^{12} \mathrm{~m}^{3}\right)$ & $4.4 \pm 0.19$ & $2.0 \pm 0.07$ & $5.2 \pm 0.3$ \\
Heat content $\left(10^{20} \mathrm{~J}\right)$ & $2.0 \pm 0.08$ & $0.9 \pm 0.03$ & $2.4 \pm 0.14$ \\
Salt content $\left(10^{12} \mathrm{~kg}\right)$ & $2.0 \pm 0.08$ & $1.0 \pm 0.03$ & $2.7 \pm 0.17$ \\
\hline
\end{tabular}

first three weeks of the R25 trajectory (Fig. 9a) show the characteristic looping pattern of a float in a translating eddy. After yearday 158 , there is an abrupt change in the nature of this looping. This change is also recognizable at yearday 165 in R24 (Fig. 9b), as well as in R21 and R10 trajectories. It becomes even more apparent in these floats when trying to fit the data to a simple model of a translating meddy using the entire trajectory of each float.

An iterative, least-squares procedure was used to fit the data piecewise, and thus describe the general motion of the meddy itself and the distance of each float from that meddy's center throughout its mission. By analyzing the first part of the float trajectories both individually and together, it was determined that they were all in a circular meddy moving in an arc. The length of each trajectory to be used for this piece of the fitting was found by comparing the residual error of the fit, starting at a subjective point, and then adding measured positions one by one until the residual error
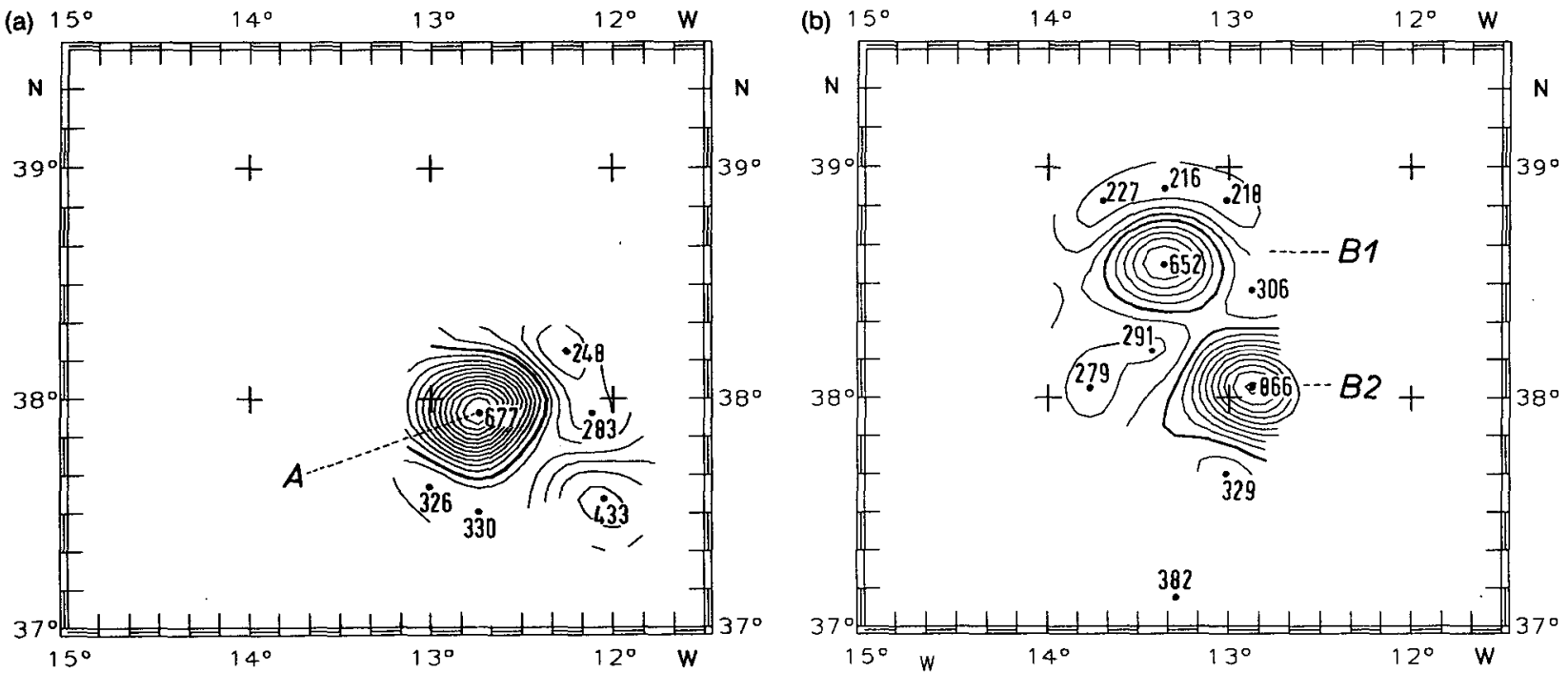

FiG. 8. Vertically integrated salt content anomaly for salinity $>35.7$ in (a) April, contour interval $25 \mathrm{~kg} \mathrm{~m}^{-2}$, and (b) May, contour interval $50 \mathrm{~kg} \mathrm{~m}^{-2}$. The heavy line marks the $400 \mathrm{~kg} \mathrm{~m}^{-2}$ contour used to define meddy dimensions (see text). 

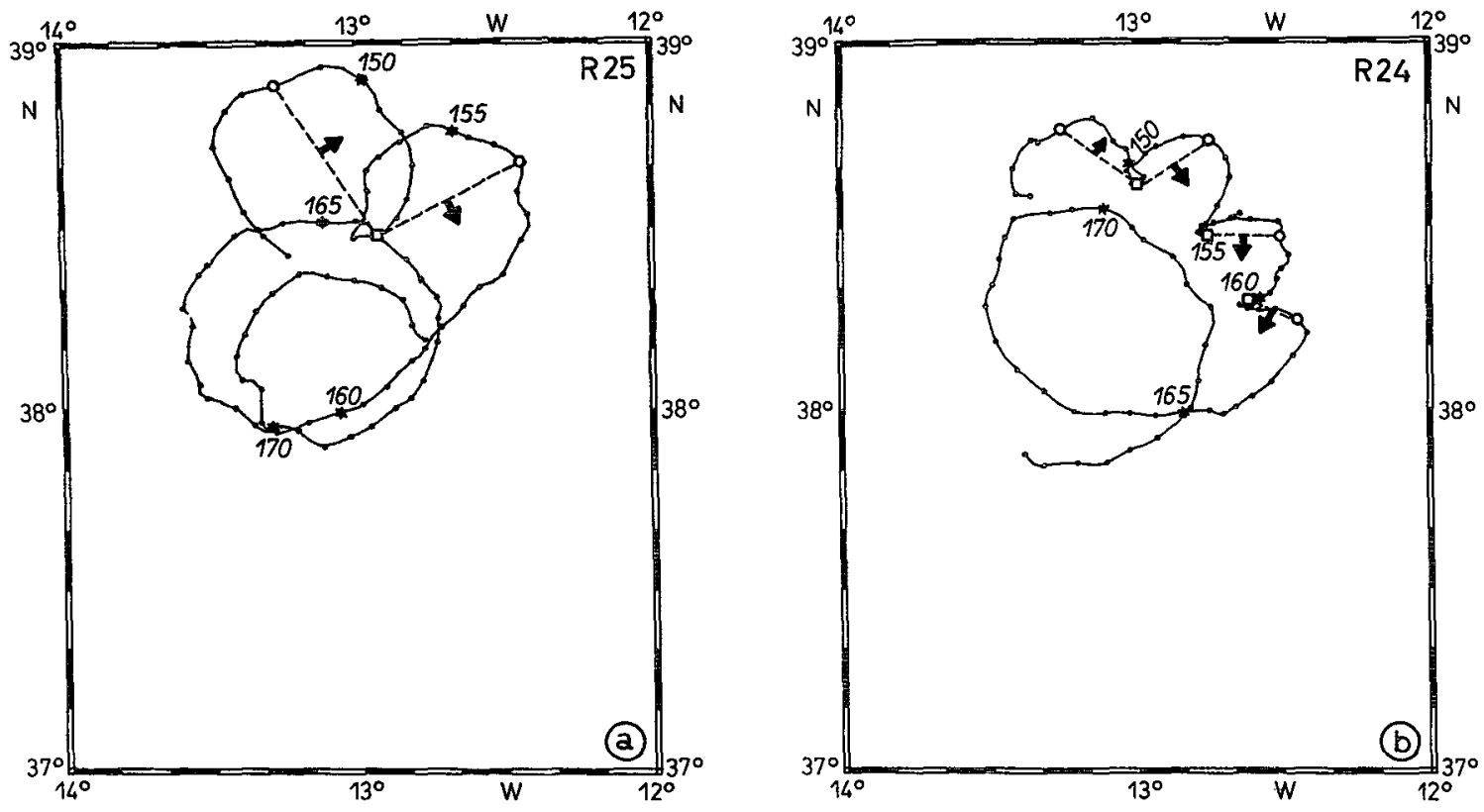

FIG. 9. RAFOS float trajectories from 8 hourly positions of (a) R24 and (b) R25. Dots mark daily positions. Starred positions labeled with yearday 1991. Dotted lines connect positions of pressure extreme (open symbols, see also Fig. 13). Arrows indicate direction $90^{\circ}$ to the right of the direction of downslope as defined by pressure maxima.

increased significantly. Thus a cutoff point was found for each float, representing the time at which those particular parameters of the model no longer hold. The

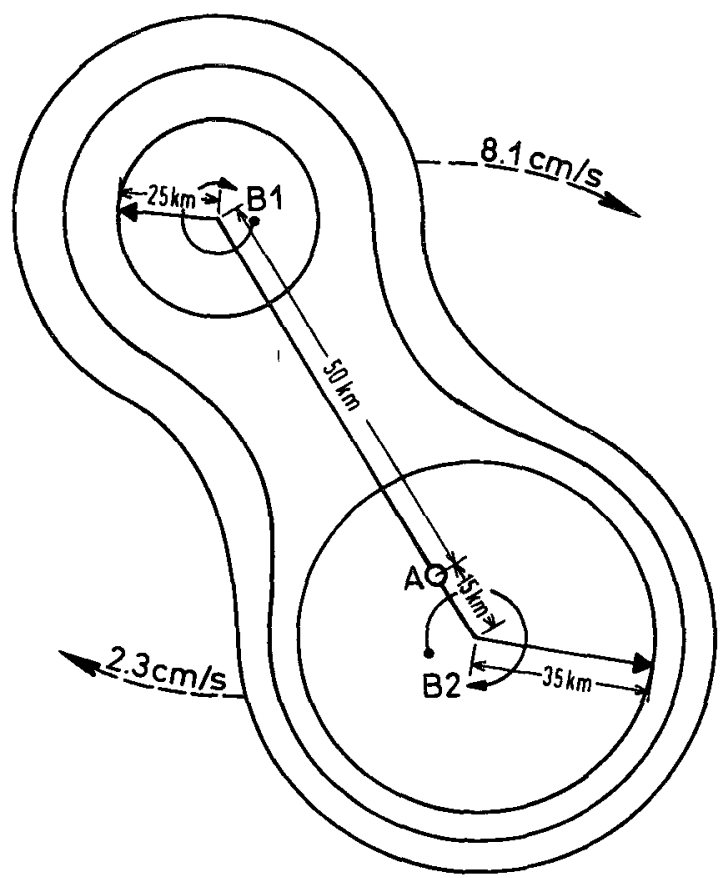

FIG. 10. Schematic of the Aska Meddy system with parameters as determined by kinematic model fit to the data. Meddies B1 and B2 revolve around common center of rotation, $A$. See text for further details. Figure not drawn to scale. fitting procedure was then repeated for the data after this cutoff point, yielding new parameters. The results of this second fit suggest that at the end of their missions the floats all rotated around a common, circular meddy with different characteristics from the first. The combination of the best-fit models yields the temporal and spatial scales shown in Fig. 10. Table 2 shows various characteristics of the floats based on this analysis.

Our interpretation of the best-fit model results describing this interaction is as follows. For at least the first three weeks, the two parts of Aska (B1 and B2) were revolving around a common center of rotation ("A," Fig. 10). Part B1, being smaller and at a radius of about $50 \mathrm{~km}$ from this center, had a core rotating with a 4.3-d period while simultaneously moving in a clockwise arc to the east at $8.1 \mathrm{~cm} \mathrm{~s}^{-1}$, which is relatively quick. Although higher translational velocities are possible in the Mediterranean Undercurrent (Zenk et al., 1992), previously observed meddies in the ocean's interior have moved at a more modest 2-3 $\mathrm{cm} \mathrm{s}^{-1}$ (Richardson et al. 1989; Armi et al. 1989; Käse et al. 1989). At a radius of $15 \mathrm{~km}$ from this center of rotation (within B2 itself), B2 moved $2.3 \mathrm{~cm} \mathrm{~s}^{-1}$ westward, resulting in the two meddy centers being $65 \mathrm{~km}$ apart. This is in good agreement with the CTD observations. The RAFOS floats showed a rotation period for $B 2$ of $8.5 \mathrm{~d}$ at a radius of $35 \mathrm{~km}$. We have no float observations in the core of $\mathrm{B} 2$, which was smaller than $35 \mathrm{~km}$ in radius, so a direct comparison with the period, and thus the relative vorticity $(\partial v / \partial r+v / r)$ of $\mathrm{B} 1$, is not possible. We have no measurement of the rotation period of the core of $\mathrm{B} 2$. 
TABLE 2. Statistics of the meddies B1 and B2 derived from float data and model fit. Ranges represent one standard deviation.

\begin{tabular}{|c|c|c|c|c|}
\hline & \multicolumn{4}{|c|}{ RAFOS float } \\
\hline & 21 & 24 & 25 & 10 \\
\hline \multicolumn{5}{|c|}{ Mean radius $(\mathrm{km})$} \\
\hline B1 & $16.6 \pm 4.7$ & $8.7 \pm 2.8$ & $19.9 \pm 4.2$ & $24.3 \pm 5.2$ \\
\hline B2 & $29.3 \pm 5.8$ & $33.8 \pm 8.0$ & $30.9 \pm 7.2$ & $40.1 \pm 5.6$ \\
\hline \multicolumn{5}{|c|}{ Mean relative velocity $\left(\mathrm{cm} \mathrm{s}^{-1}\right)$} \\
\hline B1 & $18.5 \pm 4.2$ & $14.5 \pm 5.3$ & $27.2 \pm 6.8$ & $25.8 \pm 3.3$ \\
\hline B2 & $23.3 \pm 2.0$ & $31.2 \pm 4.7$ & $27.3 \pm 4.1$ & $29.7 \pm 3.7$ \\
\hline \multicolumn{5}{|c|}{ Mean pressure (dbar) } \\
\hline B1 & $1052.6 \pm 13.0$ & $985.8 \pm 15.7$ & $1002.0 \pm 20.8$ & $862.5 \pm 26.3$ \\
\hline B2 & $1082.0 \pm 7.3$ & $1007.5 \pm 12.3$ & $1029.0 \pm 9.6$ & $879.5 \pm 9.7$ \\
\hline \multicolumn{5}{|c|}{ Mean temperature $\left({ }^{\circ} \mathrm{C}\right)$} \\
\hline B1 & $12.0 \pm 0.1$ & $12.0 \pm 0.1$ & $12.0 \pm 0.1$ & $11.8 \pm 0.1$ \\
\hline B2 & $12.0 \pm 0.1$ & $11.9 \pm 0.1$ & $12.0 \pm 0.1$ & $11.9 \pm 0.2$ \\
\hline \multicolumn{5}{|c|}{ Duration in meddy (days) } \\
\hline B1 & 9 & 18 & 11 & 5 \\
\hline $\mathrm{B} 2$ & $>5$ & $>9$ & $>15$ & 72 \\
\hline
\end{tabular}

The meddy reference frame provided by this kinematic model was used to discern some of the details of the velocity structure within B1 (see Table 2). Since the four floats covered a depth range of $200 \mathrm{~m}$, we examine only R24 and R25, both near $1000 \mathrm{~m}$. Float R25 shows a distinct trend of both decreasing cyclic velocity (not shown) and radius with time (Fig. 11). The cyclic velocity fluctuations may have two causes. The modeled meddy velocity is an average and may not coincide with the actual meddy center at the time of the measurements, or the cyclic velocity could also be due to the actual lateral movement of the float, or a combination of both. The linear trends of decreasing velocity and radius may not be explained by the float simply moving toward the center of the meddy. First, this would imply that the float was inside the radius of

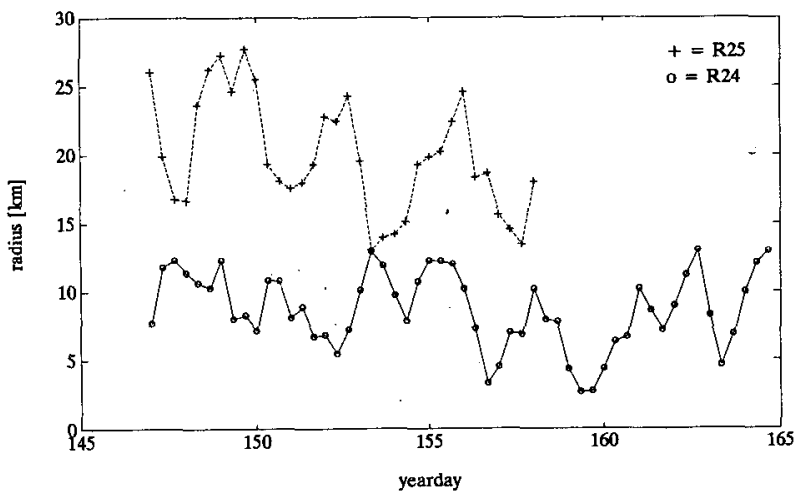

FiG. 11. Relative radial positions of floats R24 and R25 within Meddy B1 as determined by the kinematic model fit to the data, as a function of yearday 1991. Note the decreasing trend of radius with time in R25, which was outside $r_{\max }$. This trend is essentially absent in R24, which was within $r_{\max }$. maximum velocity. The individual time series showed absolute velocity and radius had an inverse relationship, and therefore the float was outside the velocity maximum. Second, the linear trend is an order of magnitude smaller $\left(1 \times 10^{-6} \mathrm{~s}^{-1}\right)$ than the velocity shear of the near solid-body core. It is more likely that the trends of decreasing radius and velocity with time are the result of the evolution of the structure of $B 1$ as it interacted with B2. With these linear trends removed, $u$ and $v$ velocities of both floats were rotated into their azimuthal $\left(v_{\theta}\right)$ and radial $\left(v_{r}\right)$ components within the moving meddy. Plotted in Fig. 12 are the resulting azimuthal velocities of the floats while they were trapped in B1 as a function of radius. Included (solid line) is the geostrophic velocity as a function of radius from

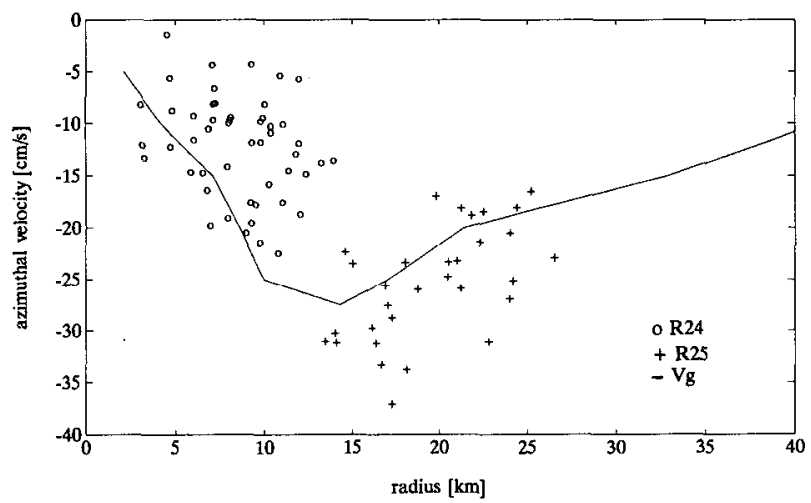

FIG. 12. Azimuthal velocity as a function of radius of $B 1$ measured by floats R24 and R 25 at $1000 \mathrm{~m}$, with linear trends in both velocity and radius removed. Points beyond two standard deviations of a linear fit with respect to radius are excluded. Measurements from R24 (O) and from R25 (+). Solid line shows geostrophic velocity from Fig. 5c. 

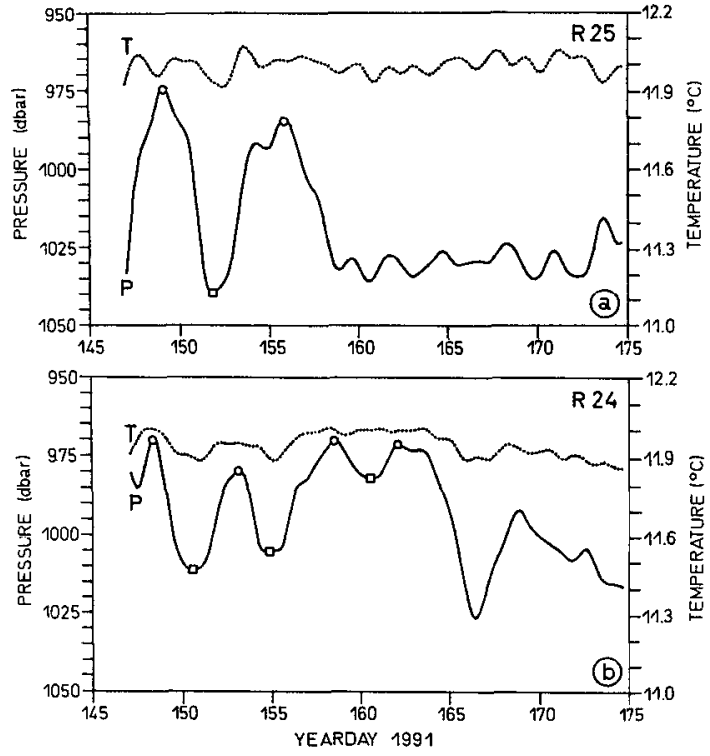

FIG. 13. Temperature and pressure records after low-pass filtering (third-order Chebyshev filter with cutoff frequency of $1 \mathrm{~d}^{-1}$ ) of (a) float R24 and (b) R25. Open circles at pressure maxima, open squares at pressure minima, as in Fig. 9.

the internal point of zero velocity (see Fig. $5 \mathrm{c}$ ). The relationship between azimuthal velocity and radius is loosely defined over the time period of a few weeks. Nonetheless, the velocity gradient changes sign at $\sim 15$ $\mathrm{km}$ radius, resulting in a vorticity front.

A much stronger, better defined front is seen in sections from quasi-synoptic Pegasus absolute velocity profiles taken in Meddy Sharon (Schultz Tokos and Rossby 1991). Lagrangian SOFAR floats also reveal a sharp transition from negative to positive relative vorticity in Sharon (Richardson et al. 1989). However, unlike Sharon, a Canary Basin meddy, the permeability or strength of the vorticity front in the Iberian Basin Meddy Aska is short lived due to the interaction with B2, and the floats soon escape. Table 2 shows that the length of time a float stayed in B1 is inversely related to its mean radius.

Aside from the different nature of rotation marked in the trajectories of these floats, the transition from B1 to B2 is also accompanied by a drop in pressure of between 20 and 30 dbar, but no significant decrease in temperature (Fig. 13, Table 2). This change in pressure of the floats can be easily explained by the buoyancy effects experienced as they enter into water of less salinity. We will discuss the pressure records of the floats in greater detail in section 5.

During the first 6 days of the float records, no floats were in B2. Nonetheless, the interpretation that B2 was revolving around a common center of vorticity with B1 is consistent with both the hydrographic observations and the subsequent float observations. From Fig. $1 \mathrm{~b}$, the center of B2 during the hydrographic survey was $38^{\circ} 05^{\prime} \mathrm{N}, 12^{\circ} 55^{\prime} \mathrm{W}$. Ten days later, $\mathrm{R} 10, \mathrm{R} 21$, and R25 were revolving around B2, with a center determined by the fit some $28 \mathrm{~km}$ to the west, resulting in a translation speed of $3.2 \mathrm{~cm} \mathrm{~s}^{-1}$. The translation velocity of $\mathrm{B} 2$ determined by the RAFOS trajectories alone is $2.3 \mathrm{~cm} \mathrm{~s}^{-1}$. These two estimates are consistent within their estimated uncertainties, as is the general direction of movement.

RAFOS float R 10 was initially launched $25 \mathrm{~km}$ from the center of $B 1$, the greatest radius of all four RAFOS floats. After only one revolution, it was entrapped by B2, and remained within the Aska Meddy system for two and a half months. Figure 14 shows the trajectory of $\mathrm{R} 10$ (solid line). The $\mathrm{R} 10$ revolved around $\mathrm{B} 2$ with an average velocity of $29 \pm 4 \mathrm{~cm} \mathrm{~s}^{-1}$, while translating at $1.5 \mathrm{~cm} \mathrm{~s}^{-1}$ to the southwest. Although R10 was outside the vorticity front (Fig. 12), which defines the core of the meddy, it remained for 10 weeks within the outer region of the meddy, still comprised of anomalously low vorticity waters. Unlike the floats in B1, while in B2, float R10 continued to migrate outward, showing an inverse relation between radius and speed $\left(r_{\max }\right.$ $<36 \mathrm{~km}$ ), until it was no longer in the meddy.

The surface drifter (Fig. 14, dotted line) confirms the surface signal of the meddy; the drifter and the RAFOS float describe the same translation of Aska of $1.5 \mathrm{~cm} \mathrm{~s}^{-1}$ to the southwest for the first three months. Surprisingly, the lower azimuthal velocity $(\bar{v}=18$ $\pm 6 \mathrm{~cm} \mathrm{~s}^{-1}$ ) of the surface drifter indicates only negligible vertical shear. The surface drifter was at a radius of $50 \mathrm{~km}$. Its average speed at that radius fits within

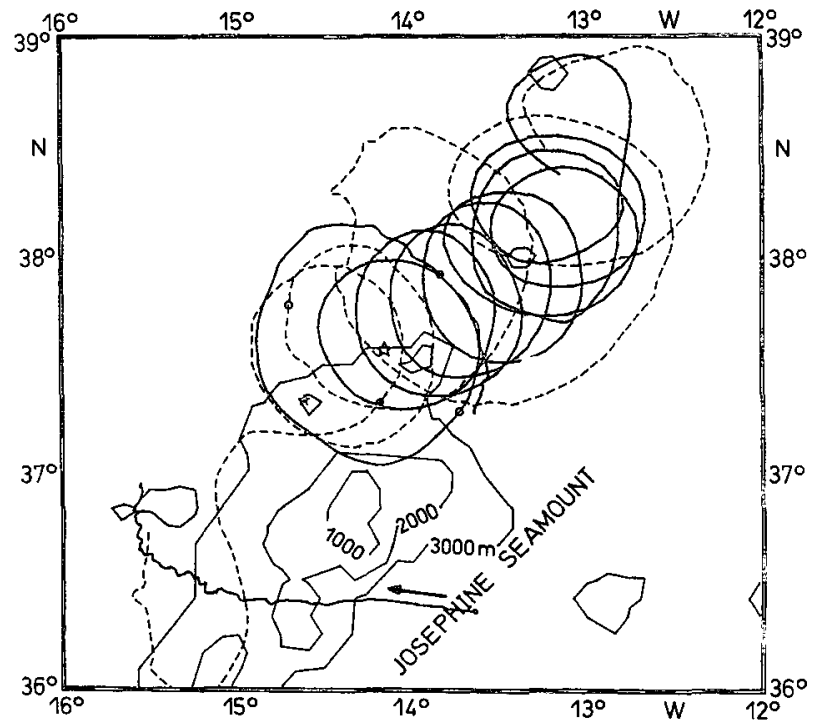

FIG. 14. Anticyclonic trajectories of R10 (solid line) and surface drifter 12275 (dotted line) overlaid on bottom contours. Open circles mark position of each on yearday 225 , while the open star marks the position of the meddy center on that day, the day on which $\mathrm{R} 10$ left the meddy. Closed circles and star mark yearday 250 , the day the surface drifter was expelled. The continuation after a gap within the RAFOS float trajectory is indicated by the arrow. 
the horizontal shear measured by R10 as it migrated outward. The RAFOS float left Aska after yearday 225 . Although it continued its anticyclonic rotation, the speeds were drastically reduced (the most definitive indication of expulsion ), the pressure decreased, and the temperature continued its steady, steplike decrease (Fig. 15).

There is a temporary gap in the RAFOS trajectory, when there was only one sound source operating. After this gap the float is clearly out of the influence of Aska, indicated for one, by the lower temperatures $\left(10.7^{\circ} \mathrm{C}\right)$, more than $1.5^{\circ} \mathrm{C}$ cooler than Aska. The float shows a weakening westward current of $3.5 \mathrm{~cm} \mathrm{~s}^{-1}$, which could be interpreted as the background flow.

\section{Vertical motion}

Another interesting characteristic exhibited by the RAFOS floats is the large variation in their pressure records (Figs. 13 and 15 ). As stated earlier, the compressibility of these floats is roughly $25 \%$ less than that of seawater. This means of the fluid parcel originally tagged by the float is displaced vertically, it will reach a new equilibrium level different from that of the float. Rossby (1988) observed vertical motion of similar floats in a Canary Basin meddy, although the vertical excursions were much less than presented here. He argues that a vertical velocity even as strong as $0.3 \mathrm{~cm} \mathrm{~s}^{-1}$ is not enough to upset the hydrostatic balance that governs a float's depth. The vertical velocities recorded by the RAFOS floats in Aska are an order of magnitude less than this critical value. Included in the appendix of Rossby (1988) is a discussion of the static response of a neutrally buoyant float to a vertical displacement of stratified water, to which the reader is referred for more details. Rossby's conclusion is that the ratio of vertical displacement of a float to that of a water parcel, $\partial z / \partial h$, is

$$
\frac{\delta z}{\delta h}=\frac{\left(\alpha_{f}-\alpha_{w}\right) \bar{T}_{z}+\beta \bar{S}_{z}}{\left(\kappa_{w}-\kappa_{f}\right) \bar{P}_{z}+\left(\alpha_{f}-\alpha_{w}\right) \bar{T}_{z}+\beta \bar{S}_{z}},
$$

where $\alpha$ is the coefficient of thermal expansion, $\beta$ the salinity expansion coefficient, $\kappa$ the compressibility, and subscripts $f$ and $w$ refer to "float" and in situ "water" parameters. Substituting applicable values for Aska, $\partial z / \partial h$ is 0.5 . From this analysis, we conclude that these floats experienced only one-half the vertical displacement of the water parcel originally tagged.

Let us first consider the vertical motion within $\mathrm{B} 1$. The most striking pressure record is that of R25 (Fig. 13a), which was at an average radius of $20 \mathrm{~km}$. The data shown have been low-pass filtered to remove the semidiurnal $O(10)$ dbar scatter. Rossby (1988) has correlated the strongest pressure variations $(O(10)$ dbar) he observed with the internal semidiurnal tide. Between yeardays 147 and 159 , a cyclic pressure variation is shown with peak-to-peak amplitude of $55 \mathrm{dbar}$ and a period of $6 \mathrm{~d}$, near the rotation period of $\mathrm{B} 1$ at

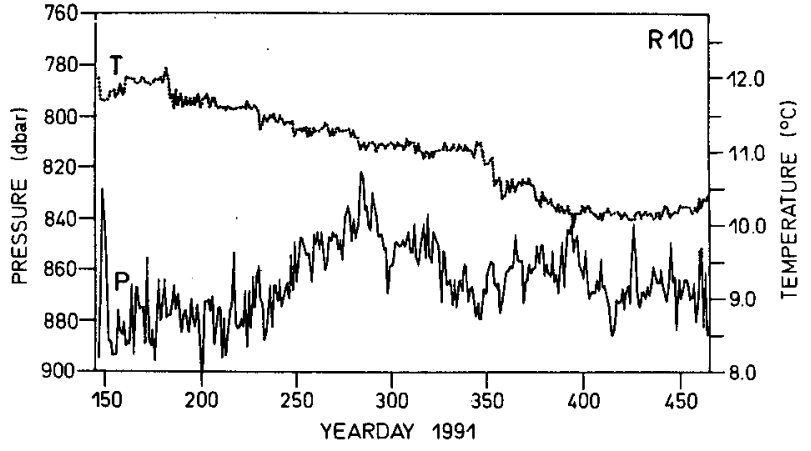

FIG. 15. Time series of pressure (solid line) and temperature (dotted line) of $\mathrm{R} 10$. The temperature decreased from $12^{\circ} \mathrm{C}$ to $10.5^{\circ} \mathrm{C}$ as the float moved outward and beyond $\mathrm{B} 1$. The decrease in pressure seen beginning at yearday 225 coincides with the expulsion of the float from the meddy.

a radius of $20 \mathrm{~km}$. This results in a vertical speed of $18 \mathrm{~m} \mathrm{~d}^{-1}$. From the above discussion, actual water parcel velocity, $w$, could be twice that, or $36 \mathrm{~m} \mathrm{~d}^{-1}$ $\left(0.4 \mathrm{~mm} \mathrm{~s}^{-1}\right)$. One can see the correlation between pressure and meddy rotation more clearly by referring to Figs. 9a and 13a. Between yeardays 147 and 159 , the float shoaled with a northward component of motion, and deepened as it moved southward.

The pressure record of R24 (Fig. 13b), with a mean radius of $9 \mathrm{~km}$, shows a similar pattern, although the peak-to-peak variations are less. Float R10 is at a larger radius of $25 \mathrm{~km}$. Although it remained in B1 only 6 days, or one revolution, there is a similar, distinct correlation of pressure to direction of movement. As seen in Figs. 14 and 15, westward and northward motion was accompanied by a shoaling of the float (days 147 to 149), eastward and southward motion by a sinking of the float (days 149 to 153 ). In the single cycle recorded, the peak-to-peak amplitude was $65 \mathrm{dbar}$.

As mentioned earlier, the transition of the floats from B1 to B2 is indicated also by their pressure records. For example, the mean pressure of R25 before day 158 is $1002 \pm 21 \mathrm{dbar}$. After yearday 158 , the pressure increases to $1030 \pm 10 \mathrm{dbar}$. The temperature, however, shows no significant change over the entire record (Fig. 13a, Table 2). If we consider this pressure change as only the result of the float moving horizontally into water with different $T-S$ characteristics, the new equilibrium depth would be due only to the salinity difference between water types. A pressure change of -30 dbar requires a decrease in salinity of $0.05 \mathrm{psu}$. The horizontal gradients from the hydrography (cf. Fig. 4) show this requires lateral movement of only a few kilometers. As the float left B1 and entered B2, the decrease in mean pressure is explained by the float's encountering less salty water at a larger radius of rotation about B2.

\section{Discussion}

When B2 was discovered, it was unclear whether it was perhaps the original meddy observed in April (A), 
or whether it was a totally new meddy entering the region. Subsequent evidence shows that B2 was a different meddy entering the region and that $\mathrm{B} 1$ was, in fact, the same meddy observed in April. The trajectory of a surface drifter launched in the center of the meddy during the first leg shows a low translational velocity $\sim 2 \mathrm{~cm} \mathrm{~s}^{-1}$ directed to the northwest. During the first 35 days, the surface drifter described an anticyclonic quasi cycloid with a radius of $10 \mathrm{~km}$. This is consistent with the initial distance of the drifter, launched $10 \mathrm{~km}$ from the meddy's center. After this time period, it left the core. The meddy B1 was then observed at the surface drifter's location $\sim 40$ days after launch and 75 $\mathrm{km}$ away, which provides evidence that $\mathrm{A}$ and $\mathrm{B} 1$ were the same meddy.

Only weak differences in temperature occurred between $A$ and $B 1$ in the depth range between 600 and $1200 \mathrm{dbar}$, whereas the range below was marked by stronger differences of up to $2.0^{\circ} \mathrm{C}$. The latter could be the result of either strong mixing due to advection of colder and fresher North Atlantic Deep Water or of double diffusive processes during the movement of the meddy toward the northwest. Similar comparisons were found for the differences in salinity. Differences between the total heat and salt content estimates of A and $B 1$ below $1200 \mathrm{~m}$ are not as well pronounced as the differences in the $T$ and $S$ profiles, but could certainly be explained by decreasing property amounts and corresponding shifts to smaller horizontal and vertical scales by intense mixing. The property comparisons confer that A and B1 were the same meddy (at different points in time), which underwent reasonable vertical decay.

The temperature and salinity fields of $\mathrm{B} 2$ observed during the second leg around $38^{\circ} 00^{\prime} \mathrm{N}, 12^{\circ} 45^{\prime} \mathrm{W}$ show it was a different meddy, not present in the survey area in April. Positive differences occur within the whole water column influenced by the Mediterranean Water between $\mathrm{B} 2$ and $\mathrm{A}$ and also between $\mathrm{B} 2$ and $\mathrm{B} 1$, with again their maximum values $\left(2.5^{\circ} \mathrm{C}, 0.5 \mathrm{psu}\right)$ between 1500 and $1800 \mathrm{dbar}$. The total heat and salt content were also significantly different, suggesting that part B2 should be recognized as a completely different meddy.

The RAFOS floats yield temporal information concerning the development of Aska. We have shown how the floats left $\mathrm{BI}$ and followed the circulation about B2, loosely defining the outer radial extent of a meddy as the radius at which a float breaks away from the closed circulation. Thus, the initial radial extent of.B1 was at least $25 \mathrm{~km}$, the distance from the center to the farthest float (Table 2). Correspondingly, B2 had a radial extent of $35 \mathrm{~km}$. Between days 155 and 165 , each float left B1 and became entrapped by B2. It is interesting to note that floats R21, R25, and R10 left $\mathrm{B} 1$, not at their maximum radial distance, but nearly at their minimum (shown for R25 in Fig. 11). In other words, the floats did not migrate steadily outward until they broke free from B1. Rather, the radial influence of B1 decreased. For example, between yeardays 147 and 156 float R25 was up to $25 \mathrm{~km}$ from B1's center and it remained trapped within the encircling flow. Therefore, we define Bl's radius during this time as at least $25 \mathrm{~km}$. By yearday 158 the radius of $\mathrm{B} 1$ had decreased to less than $18 \mathrm{~km}$, the distance at which R25 no longer remained circling $B 1$. This inward movement of the front of $7 \mathrm{~km}$ in 11 days cannot be the result of interleaving intrusions similar to those responsible for displacing the vorticity and salinity fronts in Sharon only $8 \mathrm{~km}$ in 400 days (Schultz Tokos and Rossby 1991). We postulate instead that B1 and B2 coalesced; that is, $\mathbf{B} 1$ was absorbed by $\mathbf{B} 2$.

It has been shown that the vorticity front within a meddy can act as a barrier, isolating low potential vorticity waters from the ambient ocean (Schultz Tokos and Rossby 1991). From the available data, we cannot distinguish the vorticity front in Aska from the radius of maximum velocity $r_{\max }$ at $17 \mathrm{~km}$ (Fig. 12). The reader should keep in mind that the sharpness of the front shown in Fig. 12 is lost due to the asynopticity of the measurements and the nonlinearity of the meddy translation. A synoptic view would likely reveal a better defined front. Within the core of the meddy bounded by the front, it is reasonable to assume solid-body rotation (e.g., Hedstrom and Armi 1988; Armi et al. 1989; Schultz Tokos and Rossby 1991). Using this assumption and obtaining length and velocity scales from Fig. 12, the relative vorticity $(\partial v / \partial r+v / r)$ of the core of $\mathrm{B} 1$ was $-0.4 f$. This falls in the midrange between a recently formed meddy and those farther away from their assumed source (Prater 1992).

The three floats that left B1 earliest were also outside the vorticity front. Only R24 was inside the front and stayed within the core of $\mathrm{B} 1$ over 11 days. It is interesting to note that the three floats outside $r_{\max }$ also showed a trend of decreasing radius with time within B1. This trend is absent in R24, which was inside of $r_{\max }$. One could expect the RAFOS float to remain trapped within the core waters much longer if $\mathrm{B} 2$ were an isolated meddy. However, the coalescence with B2 allowed the float and the core waters of B1 to mix with B2. No floats in B2 were able to cross the relative vorticity barrier into the core.

The only other observation of the coalescence of oceanic eddies we know of is of two warm core rings of the East Australian Current (Cresswell 1982). The rings were of different densities resulting in a vertical alignment of the two. This could not be the case with $\mathrm{B} 1$ and B2 considering their similar densities and large vertical extents. Eddy coalescence has been inodeled in the laboratory. Nof and Simmon's (1987) laboratory experiments showed repeatedly the merger of two eddies of both similar and slightly different densities. They conclude that it is a "natural tendency of lenslike vortices to unite themselves." According to Griffiths and Hopfinger (1987), coalescence should occur when the eddies are separated by a distance $<3 r_{\max }$. Applying 
this to Aska, $r_{\max }$ of $\mathrm{B} 1$, the smaller meddy, was $25 \mathrm{~km}$ and the distance between B1 and B2 $65 \mathrm{~km}$, or less than the critical distance for coalescence. The quasigeostrophic model of Beckmann and Käse (1989) presents B1 weakening until the outer circulation, which originally encompassed both meddies, describes only B2. This merging of meddies is therefore not only explainable but also probably not unique. (Nonetheless, despite abundant observations, this phenomenon has been difficult to observe.)

The surface drifter was launched at the center of B1, but no transition from $B 1$ to $B 2$ is discernible in its trajectory. Possibly the surface drifter was advected immediately into B2. More probable is that the details of the meddy system are present only at depth, where the signal maxima are. At the surface, only the outer circulation encompassing the entire system is present in the dynamic topography.

We have shown there was remarkably little vertical shear between the surface drifter and the depth of the RAFOS floats, $850-1050 \mathrm{~m}$. We can only infer the lower limit of this cohesive column of water, but it extends probably to $2000 \mathrm{~m}$, and possibly to the bottom. Aska's path led to the northwestern edge of the Josephine Seamount (Fig. 14, minimum depth 500 $\mathrm{m})$. As Aska approached the seamount, its center was already on a course coincident with the $3000-\mathrm{m}$ isobath, perhaps already due to topographic steering. It was just at the time when a seamount peak, which came to within $2000 \mathrm{~m}$ of the surface, came halfway between the center of the meddy and the float, that the float was expelled. The surface drifter, being at the float's nadir, continued around Aska for another 1.5 revolutions. Not until another $2000-\mathrm{m}$ peak was again roughly halfway between the center of the meddy and the surface drifter, was the drifter, too, expelled. It is as if the seamounts acted as a wedge to break off the outer pieces of Aska. After yearday 250, there are no further observations of Aska.

One may only speculate as to whether the meddy actually collided with the seamount and broke up, or if its path was merely deflected by the bottom topography. A meddy has been observed to disintegrate when it passed between seamounts (Richardson et al. 1989). However, Aska's collision with the Josephine Seamount was more a "side-swipe" than a "head-on" collision and there was no other seamount to restrict its deflection. In either case, the influence of the seamount was enough to expel both the RAFOS float at depth and the surface drifter. Regardless of whether Aska was destroyed by the Josephine Seamount, resulting in a sudden deposit of heat and salt, or whether Aska continued on its deflected path toward the Canary Basin, up until that point it had a transport of $1.5 \mathrm{~Sv}(75 \mathrm{~km}$ diameter $\times 1 \mathrm{~km}$ thickness $\times 2 \mathrm{~cm} \mathrm{~s}^{-1}$ translation velocity), comparable to the mass transport of the Mediterranean Overflow, but not the salt transport before entrainment.
The strong vertical motion exhibited by the RAFOS floats is an interesting aspect of B1. To explain the vertical motion, after Rossby (1988) we assume the meddy lay imbedded within an, albeit very localized, background field of tilted isopycnals with resulting geostrophic flow that advected the meddy along with it. The velocity of the flow would be simply

$$
v_{g}=\frac{g^{\prime}}{f} \tan \theta
$$

where $g^{\prime}$ is the reduced gravity and $\theta$ is the angle the isopycnals make with the horizontal. The tangent of the angle $\theta$ is calculated as the ratio of peak-to-peak pressure variations to diameter, corrected by $\delta z / \delta h$. From the CTD data, we estimate $g^{\prime}$ as $0.285 \mathrm{~cm} \mathrm{~s}^{-1}$. Then for R25, $v_{g}=8.7 \mathrm{~cm} \mathrm{~s}^{-}$. Using the tangent measured by R10, $v_{g}=8.2 \mathrm{~cm} \mathrm{~s}^{-1}$. The translation speed obtained from the model fit to the data is $8.1 \mathrm{~cm} \mathrm{~s}^{-1}$.

Looking at Fig. 9a, one can see that the direction of movement is also consistent with the tilted lens concept. The dotted lines connect pressure minima (open circles) with maxima (open squares, see also Fig. 13). The arrows show the resulting direction of geostrophic flow. In all cases, the arrows indicate an anticyclonic arc for the translation of B1. As the floats entered the much slower translating B2, the variance in pressure diminished, and no clear relationship between pressure and meddy rotation exists. This is not surprising. From the model fit, which uses data from the time period in question, the translational velocity of $\mathrm{B} 2$ is $2.3 \mathrm{~cm} \mathrm{~s}^{-1}$. Using (2), the resulting peak-to-peak pressure variations in R25 would be less than 20 dbar. This is on the same order of oscillations that we attribute to the semidiurnal tide. Assuming the $1.5 \mathrm{~cm} \mathrm{~s}^{-1}$ translational velocity measured by R 10 over the following two months, pressure variations in $\mathrm{R} 10$ due to a tilted meddy would be $17 \mathrm{dbar}$, and therefore indistinguishable in the float's pressure records.

\section{Conclusions}

From the hydrographic and float analysis, we conclude that the meddy, B1, observed in May was the same meddy as the one surveyed one month earlier in April, identified at that time as "A." Float observations, in conjunction with modeling results suggest that $B 1$ interacted and coalesced with an entirely separate, stronger meddy, B2. The resulting meddy continued on its southwestward journey, at least until it encountered the Josephine Seamount. We have no further observations after this point in time. We speculate that the dynamic equilibrium within the meddy was upset, causing both the RAFOS float and surface drifter to be expelled, and that the meddy continued on a course governed by the bottom topography.

The interaction of these Iberian Basin meddies may be typical of the region and is in contrast to the idea of solitary meddies adrift in a quiet background field, 
which may be the case in other regions like the Canary Basin. In a recent purely mathematical work, Shapiro et al. (1992) has shown the existence of two distinct meddy breeds, one in the Iberian and one in the Canary Basin. It appears that more than one type of meddy exists, which implies the possibility of multiple formation, locomotion, and decay mechanisms.

Further experiments combining observations from RAFOS floats, CTD surveys, ADCP profilers, and satellite-borne altimeters, together with numerical modeling will be necessary to reveal the role of meddies in the general circulation of the North Atlantic in more detail.

Acknowledgments. As usual with seagoing experiments, there are many individuals that have helped to make this unexpected observation of merging meddies a successful one. All floats were built and ballasted at If $M$ Kiel. We adopted the RAFOS technology from our colleague and friend Tom Rossby, University of Rhode Island. The surface buoys were kindly provided by W. Krauss. It is a pleasure to acknowledge our longlasting and ongoing collaboration with Rolf Käse with whom we discussed this material intensively. We further enjoyed the effective and friendly cooperation with Kapitän Andresen and his Poseidon crew. This work was supported by Deutsche Forschungsgemeindschaft (SFB 133).

\section{REFERENCES}

Ambar, I., L. Armi, M. O. Baringer, A. Bower, A. Fiuza, G. C. Johnson, R. Käse, M. Kennelly, E. Kunze, R. Lueck, P. Lundberg, C. G. Martins, M. D. Prater, J. Price, M. Rhein, T. Sanford, K. Schultz Tokos, J. Verrall, and W. Zenk, 1992: Outflows and overflows. Proc. Int. Workshop, University of Lisbon, Portugal.

Armi, L., D. Hebert, N. Oakey, J. Price, P. L. Richardson, T. Rossby, and B. Ruddick, 1989: Two years in the life of a Mediterranean salt lens. J. Phys. Oceanogr., 19, 354-370.

Beckmann, A., and R. H. Käse, 1989: Numerical simulation of the movement of a Mediterranean water lens. Geophys. Res. Lett., $16,65-68$

Cresswell, J., 1982: The coalescence of two East Australia Current warm-core eddies. Science, 215, 161-162.

Griffiths, R., and E. Hopfinger, 1987: Coalescing of geostrophic vortices. J. Fluid Mech., 178, 73-87.

Hebert, D., N. Oakey, and B. Ruddick, 1990: Evolution of a Mediterranean salt lens: Scalar properties. J. Phys. Oceanogr., 20, $1468-1483$

Hedstrom, K., and L. Armi, 1988: An experimental study of homogeneous lenses in a stratified rotating fluid. J. Fluid Mech., $191,535-556$.

Hiller, W., and R. H. Käse, 1983: Objective analysis of hydrographic data sets from mesoscale survey. Ber. Inst. Meereskd. Kiel, 116, $78 \mathrm{pp}$.

Hinrichsen, H.-H., M. Rhein, R. H. Käse, and W. Zenk, 1993: The Mediterranean Water tongue and its chlorofluoromethane signal in the Iberian Basin in early summer 1989. J. Geophys. Res., 98(C5), 8405-8412.

Käse, R. H., and W. Zenk, 1987: Reconstructed Mediterranean salt lens trajectories. J. Phys. Oceanogr., 17, 158-163.

-, A. Beckmann, and H.-H. Hinrichsen, 1989: Observational evidence of salt lens formation in the Iberian Basin. $J$. Geophys. Res., 94, 4905-4912.

König, H., and W. Zenk, 1992: Principles of RAFOS technology at the Institut für Meereskunde Kiel. Ber. Inst. Meereskd. Kiel, 222, 51-64.

Lillibridge, J. L., and H. T. Rossby, 1983: Property fluxes across 55W-maintaining the Mediterranean salt tongue. Eos, Trans. Amer. Geophys. Union, 64, 1089.

Maillard, C., 1986: Atlas Hydrologique de l'Atlantic Nord-Est. IFRMER, $32 \mathrm{pp}$.

McWilliams, J. C., 1985: Submesoscale, coherent vortices in the ocean. Rev. Geophys., 23, 165-182.

Nof, D., and L. Simon, 1987: Laboratory experiments in the merging of nonlinear anticyclonic eddies. J. Phys. Oceanogr., 17, 343357.

Prater, M., 1992: Observations and hypothesized generation of a meddy in the Gulf of Cadiz. Ph.D. thesis, University of Washington, $131 \mathrm{pp}$.

Richardson, P. L., D. Walsh, L. Armi, M. Schröder, and J. F. Price, 1989: Tracking three meddies with SOFAR floats. J. Phys. Oceanogr., 19, 371-383.

Rossby, T., 1988: Five drifters in a Mediterranean salt lens. DeepSea Res., 35, 1653-1663.

- - D. Dorson, and J. Fontaine, 1986: The RAFOS system. $J$. Atmos. Oceanic Technol., 3, 672-679.

Schultz Tokos, K, and H. T. Rossby, 1991: Kinematics and dynamics of a Mediterranean salt lens. J. Phys. Oceanogr., 21, 879-892.

Shapiro, G. 1., S. L. Meschanov, and M. V. Emilianov, 1992: Mediterranean lens after collision with seamounts. Okeanologia, 32, 420-427.

-_, W. Zenk, S. L. Meschanov, and K. L. Schultz Tokos, 1992: Coherency and self-similarity of the Meddy family in the eastern North Atlantic. Abstract, Sixth Annual Workshop "Laboratory Modelling of Dynamic Processes in the Ocean" of the Council on the Problems of the World Ocean, Saint Petersburg, Russ. Acad. of Sci., 55 pp.

Siedler, G., W. Zenk, and W. J. Emery, 1985: Strong-current events related to a subtropical front in the Northeast Atlantic. J. Phys. Oceanogr. 15, 885-897.

Stammer, D., H.-H. Hinrichsen, and R. H. Käse, 1991: Can meddies be detected by satellite altimetry? J. Geophys. Res., 96, 70057014 .

Worthington, V., 1976: On the North Atlantic circulation. The Johns Hopkins Oceanographic Studies, No. 6, The Johns Hopkins University Press, $110 \mathrm{pp}$.

Wüst, G., 1936: Schichtung und Zirkulation des Atlantischen Ozeans. Die Stratosphäre. Wissenschaftliche Ergebnisse der Deutschen Atlantischen Expedition auf dem Forschungs- und Vermessungsschiff "Meteor" 1925-1927, 6. Lfg., 1. Teil, $180 \mathrm{pp}$. (The stratosphere of the Atlantic Ocean, W. J. Emery, Ed., Amerind, New Dehli, 112 pp., 1978).

Zenk, W., and L. Armi, 1990: The complex spreading pattern of Mediterranean Water off the Portuguese continental slope. DeepSea Res., 37, 1805-1823.

- K. Schultz Tokos, and O. Boebel, 1992: New observations of meddy movement south of the Tejo Plateau. Geophys. Res. Lett., 19(24), 2389-2392. 